\title{
Reanalysis of English Middle Construction and Formation Conditions
}

\author{
Baijing Han \\ Foreign Language Department, Lijiang Teachers' College, Lijiang, Yunnan, China \\ Email: qingshan825003@126.com \\ Fen Xue \\ Foreign Language Department, Tourism \& Culture College of Yunnan University, Yunnan, China \\ Email: cathy6036@gmail.com
}

\begin{abstract}
The semantic function, to attribute the non-agent subject, motivates the selection of this "mismatched" argument structure of middle construction; meanwhile, it derives some restrictions on the construction as a whole as well as each of the grammatical constituents. Pre-existence makes the non-agent nominal to be a legitimate subject, but there's no qualified argument to undertake volition in middle construction.
\end{abstract}

Index Terms - middle construction, semantic function, conditions, attributee, pre-existence, volition

\section{INTRODUCTION}

Due to its unique and complex syntactic and semantic features, Middle Construction (MC) has been a hotly studied and debated topic in recent decades. However, as Oosten (1986) points out, "all the mysteries about the constraints on this construction are far from solved" (p. 164). The present study aims to reanalyze the conditions of English Middle Formation (MF).

The sentences below are the so-called middles in literature:

a. The book sells well.

b. This pen writes smoothly.

c. The lake fishes well.

d. Boca burgers cook like real meat, but they're meatless.

e. No Latin text translates easily.

All these sentences take active verb morphology but passive-like argument structures. It seems that the subjects and the predicates in such sentences conflict with each other according to the traditional active/passive dichotomy. So MC is intricate in nature though it's superficially simple in the sense that it usually consists of only three components, namely a subject, a predicate and an adverbial. Therefore, a thorough understanding of this paradoxical language phenomenon is of high practical as well as theoretical value.

\section{LITERATURE REVIEW}

Numerous studies on MC have been made from various perspectives based on different theoretical backgrounds. Concerning the focus of the present study, the essential points of various constraints on English MC available in literature can be summed up as follows.

\section{A. Constraints on Subjects}

In literature, the first influential constraint on English MC is affectedness (Hale \&Keyser, 1987; Roberts, 1987; Fagan, 1988; Pinker, 1989; Hoestra \& Roberts, 1993), according to which only the verbs with affected objects can license MC. In other words, the subject in MC must be affected by the predicate verb. This constraint, however, is either too wide or too narrow. On one hand, some middles are unacceptable though their subjects are surely affected. On the other, some others can be perfectly grammatical in spite of no affectedness to their subjects. The two-fold weakness of the affectedness constraint can be illustrated in (2) and (3).

(2) a. *The car hits easily.

b. *The door kicks with difficulty.

(3) a. I don't photograph very well.

b. Your film screens well.

Considering the inadequacy of the affectedness constraint, He (2004) puts forward the responsibility condition. That is, "the subject referent of MC has to be able to be construed as possessing properties which significantly facilitate, enable (or, as the case may be, impede) the unfolding of the process in question" (Yoshimura \& Taylor, 2004). Oosten 
(1986), Chung (1995) together with some other scholars hold a similar idea. It's easy to see that the certain properties of $I$ and your film contribute much to the process of photographing very well and screening well respectively, but it's hard to reason what kind of contribution either the car or the door makes to the process of hitting and kicking. The different acceptability between (2) and (3) lies in whether the subject can be construed to be responsible for the process denoted by the verb or not.

\section{B. Constraints on Predicate Verbs}

As for the constraints on verbs, the aspectuality condition is the one recognized most widely (Fagan, 1992; Roberts, 1987; He, 2004). It allows the activities and accomplishments to enter MC, while excluding the states and achievements.

(4) a. The truck drives easily. (activity)

b. This vase breaks easily. (achievement)

c. ${ }^{*}$ Tom believes easily. (state)

d. *The dirtiness of the street notices easily. (achievement)

However, the aspectuality condition fails to account for the unacceptability of (5)

(5) a.*Small towns destroy easily.

b. *Kidnappers do not murder easily.

Though both verbs in (5) satisfy the aspectuality condition, the middles they form are not acceptable. According to Gao (2008), MC is semi-autonomous. As a result, strong agentive verbs are incompatible with MC.

Though Gao's proposal sounds convincing, it lacks of operability for it's hard to judge whether a certain verb is too agentive or not to be licit to enter MC due to the notion of agentivity being an abstract matter of continuum. Therefore, a reliable and practical criterion or test is of great moment if Gao is on the right track.

\section{Constraints on Adverbials}

It is widely noticed that MC obligatorily requires an adverbial unless another device (negation or emphasis) is applied (Jackendoff 1972; Ernst 1984; Fellbaum 1986; Oosten 1986). Without an adverbial modification, MC couldn't contain adequate new information to satisfy Grice's conversational maxim (Goldberg \& Ackerman, 2001; Yoshimura \& Taylor, 2004).

(6) a. The car drives like a boat/ easily/365 days a year/only in the summertime.

b. *The car drives.

c. That car doesn't drive.

d. These red sports cars DO drive, don't they?

It is our default assumption that cars can be driven, middle $b$ doesn't convey any new information. So MC needs adverbial modification in most cases. However, not all adverbials are eligible for English MC.

(7) a.*The novel sells proudly.

b. *Polyester cleans carefully.

Jakendoff (1972) and Fellbaum (1986) point out that those manner adverbs that are agent-oriented are incompatible with English MC. And the adverbials in MC should be in the final positions (Hale \& Keyser, 1987).

So the adverbial in MC is restricted manywise, including its semantic orientation and position.

Up till now, the key points available in literature have been made clear. However, all those constraints mentioned above can not guarantee acceptable middles.

(8) a. English teaches easily.

b. *English learns easily.

In (8), it's absolutely plausible to construe that certain properties of English contribute much to initiating and facilitating the process of teaching as well as learning. And the verbs teach and learn are closely related in semantics. They can be considered to be the same in terms of aspectuality and similar in agentivity if not the same. Furthermore, the same adverbial easily is used at the same position. That is, both middles meet all the constraints discussed above, and share much in common, but differ a lot in acceptability. So the following sections aim to make a further exploration on the issue of English MF conditions.

\section{THEORETICAL FRAMEWORK: THE PROTO-ROLES HYPOTHESIS}

Dowty (1991) puts forward the Proto-Roles Hypothesis which treats role types as cluster concepts rather than discrete categories. Though arguments may have different degrees of membership in a role type, only two role types are sufficient to describe argument selection efficiently, namely PROTO-AGENT and PROTO-PATIENT. After generalizing possible verbal entailments about the argument in question, Dowty offers the preliminary lists of properties that characterize these two role types as below:

(1) Contributing Properties for the Agent Proto-Role:

a. volitional involvement in the event or state

b. sentience (and/or perception)

c. causing an event or change of state in another participant 
d. movement (relative to the position of another participant)

e. exists independently of the event named by the verb

(2) Contributing Properties for the Patient Proto-Role:

a. undergoes change of state

b. incremental theme

c. causally affected by another participant

d. stationary relative to movement of another participant

e. does not exist independently of the event, or not at all

Dowty points out that combinations of certain P-entailments correspond to the familiar role types.

AGENT is volition + causation + sentience + movement.

EXPERIENCER is sentience without volition or causation.

INSTRUMENT is causation + movement without volition or sentience.

THEME is most typically change + incremental-theme + dependent-existence + causally-affected.

SOURSE and GOAL are not really defined by any P-entailments, and they are obliques in many cases. In other words, oblique roles are neutral in terms of the features of Proto-Roles.

According to Dowty's argument selection principle, the argument for which the predicate entails the greatest number of Proto-Agent properties will be lexicalized as the subject of the predicate.

Though there are some verbs that entail subject existence but have none of a-d, there are apparently no verbs having any of a-d without entailing existence (for their subject) as well. In simple words, for an argument to be used as subject, it is the prerequisite to "exist independently of the event named by the verb".

\section{REANALYSIS OF MF CONDITIONS}

As mentioned already, the most salient feature of MC is that though the predicate is active in morphonology, it takes a non-agent NP as its subject. In other words, there is a superficial mismatch between the grammatical subject and the predicate. According to our study, the key to this paradox lies in three aspects: what motivates this kind of argument structure, what makes such a "mismatch" eligible and what makes it unique from others.

\section{A. Semantic Function Related Conditions}

1. The Attributee Condition

It's widely accepted that MC describes the inherent property (or properties) of the grammatical subject rather than states a certain event. Fagan (1988) notes that "middles are not used to report events, but to attribute a specific property to some object" (p.200). Condoravdi (1989) points out that MC has a generic interpretation where it predicates an inherent characteristic property of the subject meanwhile downgrading the agent. Many other scholars hold the same proposal (Fellbaum, 1986; Langacker, 2001; Yushimura \& Taylor, 2004; He, 2004; Gao, 2008).

So it is the semantic function that motivates MC to select a non-agent thematic role to be its subject, leading to such a "mismatched" argument structure. Schlesinger (1995) claims that the grammatical subject of MC should be regarded as Attributee. Based on this observation, a semantic condition for MF can be stated as:

The Attributee Condition: The subject nominal of MC must be well attributed.

The examples below illustrate how this condition works:

(9) a. *This dress fastens.

b. This dress buttons.

(10) a. *The wall hits/kicks easily.

b. The wall hits/kicks down easily.

In (9), $b$ is acceptable because it describes how a particular dress is fastened, i.e., it is newsworthy to say that a dress is buttoned rather than zipped shut or fastened in any of the other ways dresses are typically secured, but $a$ fails to attribute a specific property, for it's our default assumption that all dresses can be fastened. As for the contrasts in (10), without the participle down, it's difficult to interpret the sentence as describing a certain characteristic of the wall. While owing to the presence of down, certain property (being prone to collapsing) of the wall is manifested clearly.

2. By-product conditions

The Attributee Condition requires $\mathrm{MC}$ as a whole must attribute something to the grammatical subject, so all the constituents should contribute to this semantic function integratively. Anything against it should be filtered out. Further examination in this line shows that all the constraints discussed in literature review are just some by-products of the Attributee Condition.

a. The Attributee Condition and the constraints on adverbials

It's widely noticed that adverbials are obligatory. However, This dress buttons shows that as long as the grammatical subject can be attributed properly, the adverbial is not a must albeit no other syntactic device is applied. Of course, adverbials are necessary in most cases, but agent-oriented ones absolutely contradict with MC for MC focuses onto attributing the non-agent subject, naturally suppressing or backgrounding the role of the agent.

In fact, the same adverbial in different positions may induce different interpretations (Jakendoff, 1972). The adverbial at final describes the process manner; by contrast, the one in initial modifies the entire predicate (clause), thus 
suggestive of the result of an event. English MC expresses the facility of initiating an event instead of the result of the event (Gao, 2008). Adverbials in MC must occupy the final positions.

b. The Attributee Condition and the responsibility condition

The event employed to attribute a nominal should be the one in which the referent of this nominal contributes much. If the referent plays a so trivial role in an event, it's surely not a proper case to reveal its attribute. In a sense, the Attributee Condition and the Responsibility Condition are mutual in spite of inverse perspectives. That can be illustrated by (11).

(11) a. The chamomile cures well.

b. *The scalpel cures well.

In the process of curing a patient, medicine (the chamomile) contributes much more than the scalpel does. Correspondingly, in the same process, the chamomile can be attributed well, but the scalpel not.

c. The Attributee Condition and the aspectuality condition

According to the Attributee Condition, MC must be able to depict the inherent and constant property of the subject referent. That is, the Attributee Condition also entails MC into a generic interpretation. Middles "state propositions that are held to be generally true [...] they do not describe particular events in time" (Keyser \& Roeper, 1984, p.384). So Roberts (1987) claims that "middle formation is a process of stativization" (p.196). In other words, MF undergoes a process of imperfectivization. Of course only perfective verbs can be imperfectivized. Since state and achievement verbs are already imperfective, they can not be further imperfectivized. So the so-called aspectuality condition is subject to the Attributee Condition in essence.

d. The Attributee Condition and the agentivity condition

As analyzed already, due to the semantic function, MC backgrounds the role of the agent semantically, in fact suppresses it syntactically usually. As a result, strong agentive verbs should be filtered out. The operable criterion to test whether a certain is too agentive to enter MC will be figured out later.

It's clear that all those MF conditions proposed up till now are just some requirements for each constituent in MC to work compatibly to realize its semantic function as a whole. All of them are subject to the Attributee Condition in nature. But the Attributee Condition only presents the motivation to select such a "mismatched" argument structure, leaving the question what makes it grammatical and unique untouched. The next section aims to unravel such mysteries mainly based on the Proto-Roles Hypothesis.

\section{B. Subjecthood Related Conditions}

1. The Pre-existence Condition

Many scholars (Fagan,1992; Gao 2008; Oosten 1977,1986; Voorst 1988. Yushimura \& Taylor 2004) argue that the non-agent subject of MC appears to play an agent-like role in the sense that this nominal, due to its prominent properties, can be construed to be responsible for the occurrence of the event involved. According to Lakoff (1977), responsibility "is the most central ... of all the agent properties that typically pair with subjecthood" (p.249).

The term responsibility functions the same as one of Dowty's Contributing Properties for the Agent Proto-Role, "causing an event or change of state". Though causation is an important and prominent feature of subjecthood, it's not the basic one. That's why the responsibility condition proves to be untenable.

According to Dowty (1991), what is vital for a non-agent nominal to be the qualified subject is independent existence. Similarly, Manabu Kusayama (1998) concludes that pre-existence is the basic one among various features of the Agent. The notion of pre-existence overlaps with Dowty's independent existence. It's theoretically safe to take pre-existence as the basic and vital feature of subjecthood. Thus another MF condition can be assumed as bellow:

The Pre-existence Condition: The referent of the MC subject must be pre-existent prior to the event named by the main verb.

Typically, the objects created do not exist until the process of creating. Just as Fellbaum (1986) notices "the verbs referring to the creation of the object denoted by the patient NP can not be employed in middles" (p.17).

(12) a. *This house builds easily.

b. *This poem writes easily.

The domain of 'existence' relevant to the notion of pre-existence is not limited to a physical one; instead, it can be extended to the metaphorical or abstract.

(13) a. French teaches easily.

b. *French learns easily.

(14) a. The books sell well.

b. *The books buy well.

Such data are hardly accounted for and known as notorious pairs in literature. But the differences between each pair are apparent when the notion of pre-existence in abstract domain is applied. Because what is learned is commonly regarded as coming into existence in the learner's domain of knowledge after the action of learning. Similarly, what is bought is not coming into existence in the buyer's domain of possession or ownership until the transaction of buying. In each pair, the latter's failing to satisfy the Pre-existence Condition leads to unacceptability.

But it should be noticed that the Pre-existence Condition imposes unbalanced effects on MF in the generic and specific contrasts, as shown in (15) and (16) respectively: 
(15) a. *This wool sweater knits easily. (specific)

b. *This bridge builds easily. (specific)

(16) a. ?Wool sweaters knit easily. (generic)

b. ?This type of bridge builds easily. (generic)

For the specific sentences in (15), the Pre-existence Condition works forcefully. But for the generic counterparts in (16), different scholars have different judgments. Fellbaum (1986) regards them unacceptable. However, in the eyes of Achema \& Schoorlemmer, they are unproblematic. A natural question is why the generic ones are more acceptable though they all contradict the Pre-existence Condition literally.

According to He (2004), the concept of blueprint or schema works here. The generic ones are comparatively easier to activate the relevant blueprints which in turn facilitate the interpretation of such sentences. That is, the Pre-existence Condition is satisfied with the schematic knowledge of the same categorical referents in our mind. In contrast, it's not so easy for sentences with specific subjects, which refers to entities only coming into existence as a result of the very action in question. So we argue that the Pre-existence Condition surely exists there linguistically though world knowledge impacts our grammatical judgments substantially.

2. The Strong Volitional Condition

According to Dowty, all the arguments in the subject position of MC are of certain degree of the resemblance to Proto-Agent, some possess more features of Proto-Agent, and some others fewer. But it doesn't mean that they are Proto-Agents themselves. Then what after all makes them distinguishable?

With a thorough comparison between the features of Proto-Agent and the ones of all other non-agent roles, it would be clear that all but one contributing property of Proto-Agent can be possibly shared by other non-agent roles. That is the "volitional involvement in the event or state". So the grammatical subjects of MC do not qualify to undertake the property of volition.

Furthermore, it's widely accepted that the agent is implicit or depressed in MC. All these facts show that there is no argument that is capable of taking on the property of VOLITION in MC. If a verb in MC necessarily entails strong volitional involvement of agent, it is ungrammatical. So another condition for MF goes like this:

\section{The Strong Volitional Condition: Any verbs necessarily entailing strong VOLITION are incompatible with MC.}

Of course, most verbs, except for unaccusatives, have the potential to entail volition. For example, John is being polite to Bill/ is ignoring Mary. Then, how can we make a judgment whether a certain verb can meet the Strong Volitional Condition or not? What is the criterion or testing method?

Admittedly most verbs are possible to entail volition, we argue that only the ones necessarily entailing strong VOLITION can not enter English MC. Agents must be always involved volitionally in the events denoted by such verbs, no volition involved, no such events would happen, for the volition is a prominent aspect of such verbs' inherent semantics. So for a sentence with a strong-volition verb, it surely indicates that the agent carries out the event deliberately or intentionally, or engages in it carefully or cautiously no matter such an adverbial modification exists explicitly or not. It would be very odd or unreasonable if a sentence simultaneously takes a strong-volition verb and an adverbial indicating no or weak volition. For example:

(17) a. ??The enemy destroyed our cities without intention.

b. ??The politicians carelessly murdered President Lincoln.

Based on such an observation, it is concluded that if a verb is semantically incompatible with an adverbial indicating weak or no volition, it can be regarded of strong volition, in turn, it's incompatible with MC. Thus the Strong Volitional Condition of MF is much more operable though it's related to the agentivity condition in a sense.

\section{CONClusion}

In this article, we have attempted to solve two interweaving problems about English MC, to reanalyze the MF conditions and unravel the mysteries about the paradoxical argument structure from three perspectives: what motivates such a "mismatched" argument structure, what licenses it and what makes it unique from others.

First, MC as a whole functions to characterize a non-agent argument, naturally this construction downgrades the role of the agent, so the superficially mismatched argument structure is selected. In order to manifest this semantic function, the subject referent must be attributed well, and all the constituents in MC have to contribute to it cooperatively. And this semantic function also entails MF into a process of imperfectivization. Thus all the conditions discussed in section II come into being which are subject to the Attributee Condition in nature.

Second, pre-existence is the basic and vital property for non-agent arguments to be qualified subjects. The Pre-existence Condition is there to make this "mismatched" argument structure linguistically legitimate.

Third, it is volition that distinguishes the grammatical subject of MC from other agent subjects. MF should meet the Strong Volition Condition to exclude verbs which semantically clash with its subject.

To sum up, the semantic function selects the argument structure; in turn it derives some specific restrictions on the construction as a whole as well as the individual lexical items in it. The Proto-Roles Hypothesis enlightens us much as to the paradoxical language phenomenon. "Middles involve a complex interplay between syntax, semantics and lexicon, and thus provide a rich source of data with which theories of grammar can be tested" (Fagan,1992, p.4).

Of course, the proper characterization of the verbs that can undergo middle formation, the question what exactly 
makes these verbs different from those that are not eligible for this process, are notoriously difficult questions (Ackema \& Schoorlemmer, 2005). We are not to say the present study can solve all the mysteries about this superficially mismatched argument structure completely, however, it does shed light onto the nature of MC, especially in terms of MF conditions.

\section{REFERENCES}

[1] Ackema, p. \& Schoorlemmer, M. (2005). Middles. In Everaert, M. \& van Riemsdijk, H. (Eds.), The Blackwell companion to syntax, Oxford: Blackwell Publishing, 131-203.

[2] Chung, Taegoo. (1995). A semantic sondition on English Middles: A Causative Approach. Korean Journal of Linguistics, 20 , 271-288.

[3] Condoravdi, C. (1989). The Middle: where semantics and morphology meet. MIT Working Papers in linguistics, 11, 18-30.

[4] Dowty, David. (1991). Thematic Proto-roles and argument selection. Language, 67, 547-619.

[5] Ernst, Thomas. (1984). Towards an integrated theory of adverb position in English. Bloomington: Indiana University Linguistics Club.

[6] Fagan, Sourace. (1988). The English Middle. Linguistic Inquiry,19,181-203.

[7] Fagan, Sourace. (1992). The Syntax and Semantics of middle constructions: a study with special reference to German. Cambridge: Cambridge University Press.

[8] Fellbaum, C. (1986). On the Middle Construction in English. Bloomington: Indiana University Linguistic Club.

[9] Goldberg, A. E. \& Ackerman F. (2001). The pragmatics of obligatory adjuncts. Language, 77, 798-814.

[10] Hale, K. \& Keyser S. J. (1987). A view from the middle. Lexicon Project Working Papers 10, Center for Cognitive Science. Cambridge, MA: MIT, Center for Cognitive Science.

[11] Hoekstra, Teun \& Ian Roberts. (1993). Middle Constructions in Dutch and English. Knowledge and Language, 2, $183-220$.

[12] Jaekendoff, Ray. (1972). Semantic Interpretation in Generative Grammar. Cambridge: MIT Press.

[13] Keyser, S. J. \& T. Roeper. (1984). On the middle and ergative constructions in English. Linguistic Inquiry, 15, 381-416.

[14] Kusayama Manabu. (1998). Middle and tough-constructions in English. Tsukuba English Studies, 17, 201-219.

[15] Lakoff, G. (1977). Linguistic gestalts. Chicago Linguistic Society, 13, 236-87.

[16] Langacker, R. W. (2001). Discourse in Cognitive Grammar. Cognitive Linguistics, 12, 143-188.

[17] Pinker, S. (1989). Learnability and cognition: The acquisition of argument structure. Cambridge: MIT Press.

[18] Roberts, I. (1987). The representation of implicit and dethematized subjeets. Dordrecht: Foris.

[19] Schlesinger, I. M. (1995). Cognitive space and linguistic case. Cambridge: CUP.

[20] van Oosten, J. (1986). The Nature of Subjects, Topics and Agents: A cognitive Explanation. Bloomington: Indiana University Linguistics Club (IULC) Publications.

[21] van Voorst, J. V. (1988). Event structure. Amsterdam: John Benjamins.

[22] Wenzhong, He. (2004). Middle constructions in Chinese and West Germanic languages: Towards a unified cognitive account. Shanghai International Studies University, China.

[23] Yoshimura, K. \& Taylor, J. R. (2004). What makes a good middle? English Language and Linguistics, 8, $293-321$.

[24] Yusong, Gao. (2008). L2 acquisition of English MC and its related structures by Chinese and Korean learners: towards an event structure-based account. Unpublished doctorial dissertation. Guangdong University of Foreign Studies, China.

Baijing Han was born in Gansu, China in 1982. He got his M.A. degree in English Teaching Methodology from Northwest Normal University, China in 2010.

He's now a teacher in Foreign Language Department, Lijiang Teachers' College, Yunnan, China. His academic interests include cognitive linguistics and comparative study of Chinese and English.

Fen Xue was born in Shanxi, China in 1983. She got her M.A. degree in English Teaching Methodology from Northwest Normal University, China in 2010.

She's now a teacher in Foreign Language Department, Tourism \& Culture College of Yunnan University, Yunnan, China. She's interested in applied linguistics and second language acquisition. 